\title{
DIRETRIZES PARA ELABORAÇÃO DE ARTIGOS TECNOLÓGICOS, ARTIGOS APLICADOS OU RELATOS TÉCNICOS DE PRODUÇÃO COM ÊNFASE PROFISSIONAL
}

\author{
Cristina Dai Prá Martens \\ Editora Chefe da IPTEC \\ Doutora em Administração \\ Universidade Nove de Julho - UNINOVE \\ São Paulo - SP - Brasil \\ cristinadm@uni9.pro.br \\ Cristiane Drebes Pedron \\ Editora Científica da IPTEC \\ Doutora em Gestão \\ Universidade Nove de Julho - UNINOVE \\ São Paulo - SP - Brasil \\ cdpedron@uni9.pro.br \\ (D) Jairo Cardoso de Oliveira \\ Editor Associado da IPTEC \\ SPI Integração de Sistemas - SPI \\ São Caetano do Sul - São Paulo - Brasil \\ jairo.cardoso13@gmail.com
}

\section{$\underline{\text { Cite como }}$}

American Psychological Association (APA)

Martens, C. D. P., Pedron, C. D., \& Oliveira, J. C. (2021, jul./dez.). Editorial. Diretrizes para elaboração de artigos tecnológicos, artigos aplicados ou relatos técnicos de produção com ênfase profissional. Revista Inovação, Projetos e Tecnologias - IPTEC, São Paulo, 9(2), 143-147. https://doi.org/10.5585/iptec.v9i2.21117.

Artigos tecnológicos - também denominados de relatos técnicos ou de artigos aplicados - são trabalhos com uma abordagem focada na solução de problemas de caráter prático, mas sem deixar de lado o rigor científico (Biancolino, Kniess, Maccari, \& Rabechini Jr., 2012). Segundo Motta (2017), artigos tecnológicos são produções com ênfase profissional, cujo objetivo é apresentar solução para um problema. São, portanto, estudos que propiciam contribuições para o contexto prático profissional, cuja principal característica é o enfoque na resolução de problemas. 
A comparação entre artigos tecnológicos e artigos científicos permite melhor clareza em sua distinção: um artigo científico tem ênfase na descrição, na explicação ou na predição de certo fenômeno; um artigo tecnológico tem ênfase na solução de problemas ou em oportunidades de melhorias em contexto profissional. Espera-se que o artigo tecnológico traga como contribuição algum tipo de novidade para o contexto estudado em termos de soluções ou de aplicação da solução. Ele também deve ter uma redação caracterizada por linguagem acessível a sua audiência, que em geral é formada não apenas por acadêmicos, mas por profissionais de mercado.

Um bom artigo tecnológico deve ter algumas características específicas, entre as quais destacamos as que consideramos principais:

1. Deve explorar a situação problema a ser resolvida ou a oportunidade de melhoria a ser desenvolvida.

2. Deve fazer uso da literatura para compreensão do tema de estudo, e para embasamento teórico de potenciais soluções e da proposta de intervenção.

3. Deve usar o método científico para o desenvolvimento dos procedimentos que levam à solução do problema (relatar o tipo de intervenção e os mecanismos adotados, as técnicas utilizadas para coleta e análise dos dados, bem como o detalhamento dos procedimentos realizados ao longo da pesquisa).

4. Deve apresentar alguma novidade nos resultados, ou seja, que os resultados sejam caracterizados como extrapolação, melhoria ou inovação. A extrapolação retrata soluções conhecidas aplicadas a novos problemas; a melhoria representa novas soluções para problemas conhecidos; a inovação, neste contexto, trata de novas soluções para novos problemas (Gregor \& Hevner, 2013). Importante lembrar que mesmo que os resultados obtidos na pesquisa não tenham sido aqueles esperados de acordo com a fundamentação teórica, esse não é necessariamente um motivo para invalidar o artigo tecnológico. Apresentar uma argumentação que indique os motivos desse descolamento também se enquadra como uma novidade nos resultados.

5. Deve esclarecer as contribuições para a prática profissional e para a área de conhecimento, bem como a relevância dos resultados para outros casos similares. Isso porque, em geral, os artigos tecnológicos são aplicados a um contexto ou a um caso específico. 

artigos tecnológicos, artigos aplicados ou relatos técnicos de producão com ênfase profissional.

Cabe salientar que alguns trabalhos não se caracterizam como artigos tecnológicos. Um exemplo é a simples aplicação de soluções conhecidas para problemas conhecidos, que não resulta em inovação, melhoria ou extrapolação, que mais se caracteriza como um caso de ensino (Motta, 2017). Também não se caracterizam como artigos tecnológicos as revisões sistemáticas de literatura, as bibliometrias e a maioria das surveys (a menos que ela resulte em uma clara contribuição de caráter prático-profissional).

A seguir, apresentamos um checklist para revisão de artigos tecnológicos no intuito de auxiliar os autores na elaboração ou aprimoramento de seu documento, bem como os revisores deste tipo de produção.

\section{Introdução:}

- O tema foi apresentado?

- O problema a ser resolvido/relatado ou a oportunidade de melhoria traz argumentos práticos e teóricos?

- O objetivo do estudo foi claramente apresentado?

- A intervenção prática foi brevemente relatada?

\section{Fundamentação teórica:}

- Foi apresentada literatura que permita a compreensão do tema de estudo?

- Existem argumentos teóricos que permitem o embasamento da proposta de intervenção?

\section{Método:}

- A escolha metodológica foi fundamentada?

- Esta escolha é coerente com o objetivo do estudo?

- Existe detalhamento sobre as formas de coleta de dados?

- Existe detalhamento sobre como os dados foram analisados?

\section{Análise e discussão dos resultados:}

- Foi realizada a caracterização da organização e do problema no contexto investigado?

- Foi apresentada a intervenção desenvolvida com descrição das atividades realizadas para solucionar o problema? 
- A descrição dos resultados obtidos e sua análise consideraram a literatura de base apresentada na fundamentação teórica?

\section{Conclusão e contribuições:}

- Existem evidências que os objetivos propostos foram atingidos?

- Foram apresentadas as contribuições do estudo para a prática profissional e para a área de conhecimento?

- Quais foram os aprendizados decorrentes do estudo?

- Qual a relevância dos resultados do estudo para outros casos similares?

- Quais as limitações do estudo e suas implicações?

- Foram apresentadas sugestões de estudos futuros?

\section{Aspectos de formato:}

- Todas as referências citadas no texto estão listadas no final do documento, na seção de Referências?

- Todas as referências listadas no final são, de fato, citadas no texto?

- O documento atende as normas da APA? (para o caso da IPTEC)

- As regras gramaticais foram atendidas?

- O texto está no formato solicitado no site da Revista?

Por fim, vale lembrar que problemas da prática profissional são campos frutíferos para a definição de problemas de pesquisa de trabalhos de ênfase profissional (Martens \& Pedron, 2019). Nesse sentido, entendemos que a elaboração de um artigo tecnológico apresenta certo desafio pela necessidade de conexão com a prática profissional. No contexto brasileiro, percebemos que existe menos concorrência para a publicação de artigos tecnológicos do que de artigos científicos, assim, um artigo tecnológico bem elaborado certamente terá aceitação em periódicos que publicam este tipo de produção.

Convidamos a todos a submeterem seus artigos tecnológicos, seus artigos aplicados ou seus relatos técnicos para a Revista IPTEC. 

artigos tecnológicos, artigos aplicados ou relatos técnicos de producão com ênfase profissional.

\section{Referências}

Biancolino, C. A., Kniess, C. T., Maccari, E., \& Rabechini Jr, R. (2011). Protocolo para elaboração de relatos de produção técnica. Revista de Gestão e Projetos, 3(2), 294-307.

Gregor, S., \& Hevner, A. R. (2013). Positioning and presenting design science research for maximum impact. MIS Quarterly, 37(2), 337-355.

Martens, C. D. P., \& Pedron, C. D. (2019). A Disseminação da Produção Técnica/Tecnológica Gerada em Programas Stricto Sensu Profissionais. Revista Inovação, Projetos e Tecnologias, 7(1), 1-3.

Motta, G. D. S. (2017). Como escrever um bom artigo tecnológico? Revista de Administração Contemporânea, 21(5), 4-8. 